\title{
OS INSTRUMENTOS LEGAIS DE GESTÃO AMBIENTAL E SUA RELAÇÃO COM OS PRINCÍPIOS DA ECONOMIA CIRCULAR
}

\author{
Lorena Tibúrcio Stival \\ Instituto Federal de Goiás, Goiânia -GO \\ lorenatstival@hotmail.com \\ Rosana Gonçalves Barros \\ Instituto Federal de Goiás, Goiânia -GO \\ rosana.ifg@gmail.com \\ Rosângela Mendanha da Veiga \\ Instituto Federal de Goiás, Goiânia -GO \\ rmdaveiga.ifg@gmail.com
}

\begin{abstract}
RESUMO
A Economia Circular é definida como um novo modelo econômico e produtivo que é baseado em ciclos fechados e regenerativos. Explorando o tema mais a fundo, entende-se que a inclusão dos princípios da Economia Circular nos instrumentos legais é necessária para que eles sejam colocados em prática. Diante desta premissa, o presente estudo teve como objetivo apresentar a Economia Circular e analisar os instrumentos legais brasileiros voltados para a gestão ambiental, no nível nacional e estadual, a fim de identificar a existência, ou a não existência, dos princípios da Economia Circular nas mesmas. A metodologia utilizada foi a pesquisa bibliográfica exploratória seguida de análise crítica e interpretação das informações coletadas. Para o embasamento teórico, foram utilizados os autores relacionados à Economia Circular. De acordo com o estudo bibliográfico desenvolvido, foi possível mostrar que quase não se encontram os princípios da Economia Circular nos instrumentos legais de gestão ambiental pública brasileira. Por fim, fo constatado que a adequação e o amadurecimento dos instrumentos legais de gestão ambiental pública em relação aos princípios da Economia Circular são necessários, acompanhando as novas tendências econômicas mundiais.
\end{abstract}

Palavras-chave: Economia Linear. Gestão Ambiental Pública. Política Nacional de Meio Ambiente. Política Nacional de Resíduos Sólidos.

\section{PUBLIC POLICIES OF ENVIRONMENTAL MANAGEMENT AND ITS RELATION TO CIRCULAR ECONOMY'S PRINCIPLES}

\begin{abstract}
The Circular Economy is defined as a new economic and productive model that is based on closed and regenerative cycles. Furthermore, it was understood that the inclusion of Circular Economy's principles in legal instruments is necessary to put it into practice. Based on this premise, this study aimed to present the Circular Economy and analyze the Brazilian legal instruments for environmental management, at the national and state levels, intending to identify the existence, or non-existence, of Circular Economy's principles. The theoretical background was based on main authors regarding to the Circular Economy. From this reading, it was done a critical analysis and interpretation of the collected information. According to the bibliographic study developed, it was possible to show that the Circular Economy's principles are quite absent in the Brazilian public environmental management legal instruments. Moreover, it was found that the adequacy and maturing of the public environmental management legal instruments in relation to the Circular Economy's principles are necessary, following the new world economic trends.
\end{abstract}

Keywords: Linear Economy. Public Environmental Management. National Environmental Policy. National Solid Waste Management Policy. 


\section{INTRODUÇÃO}

A produção de resíduos sólidos na sociedade brasileira é contínua e acontece sempre que algum material, substância, objeto ou algum bem é considerado inutilizável pelos seus usuários. Estabelecendo uma relação entre população e produção de resíduos sólidos, pode-se afirmar que esses são elementos diretamente proporcionais: quanto maior o número de pessoas, maior será a geração de resíduos sólidos, assim é descrito nas principais obras técnicas referentes à gestão e ao gerenciamento de resíduos sólidos (MONTEIRO, 2001; VILHENA, 2018). De acordo com o Instituto Brasileiro de Geografia e Estatística (IBGE) (2010), sua Pesquisa Nacional de Saneamento Básico (PNSB) abordou a questão da destinação final destes resíduos, e revelou que até o ano de 2008 , $50,8 \%$ dos resíduos sólidos eram destinados ao vazadouro a céu aberto, $22,5 \%$ ao aterro controlado e $27,7 \%$ ao aterro sanitário. Percebe-se então, que há uma defasagem em relação ao alcance das políticas públicas ambientais e de resíduos sólidos no Brasil.

Adentrando ao contexto da União Europeia, constata-se que suas políticas públicas relativas à gestão ambiental e de resíduos sólidos são modificadas costantemente visando à eliminação dos resíduos na Europa, modificações estas, que têm como base os princípios de uma economia cíclica: a Economia Circular. Nota-se por isso, que a constante atualização e evolução dos instrumentos legais são indispensáveis para que os princípios da Economia Circular sejam incorporados e colocados em prática na gestão ambiental de um país.

Neste sentido, o presente estudo teve como objetivo apresentar a Economia Circular e analisar os instrumentos legais brasileiros voltados para a gestão ambiental, no nível nacional e estadual, a fim de identificar a existência, ou a não existência, dos princípios da Economia Circular nas mesmas. Para tanto, foi elaborado um referencial teórico sobre a Economia Circular, e foi feito um levantamento dos principais instrumentos legais, que dizem respeito à gestão ambiental pública no Brasil e no Estado de Goiás.

\section{ECONOMIA CIRCULAR: CONCEITO, PRINCÍPIOS E CARACTERÍSTICAS}

De acordo com Ellen MacArthur Foundation (EMF) (2013a), Economia Circular é um modelo de produção regenerativo, em que o ciclo é fechado. Neste sistema, produtos, componentes e materiais são mantidos dentro do ciclo produtivo, até seu último valor, sendo reincorporados, posteriormente, pelos ciclos biogeoquímicos ou tecnológicos.

O termo Economia Circular pode ser definido como o contrário da Economia Linear, o modelo econômico que perdura atualmente, baseado em extrair, transformar e descartar. Murray, Skene e Haynes (2015) pontuam que este tipo de produção linear leva a impactos ambientais negativos de dois modos: (I) a redução do volume e (II) do valor do capital natural. O volume do capital natural é reduzido, pois ele é extraído do meio natural para ser usado como matéria prima; (II) e o seu valor também é reduzido, pois o produto final, quando transformado em resíduo é considerado um agente poluidor, constituindo-se em uma externalidade negativa dos processos produtivos, perdendo assim, seu valor econômico.

\section{Economia Circular: origem e histórico}

A economia mundial, nela inseridos o Brasil e o Estado de Goiás, é pautada por um modelo econômico baseado na exploração dos recursos naturais finitos, em sua conversão em produtos que após o uso são descartados. Dessa forma, o aumento demográfico mundial contínuo sugere que a exploração dos recursos naturais tende a aumentar de forma exponencial para atender os crescentes níveis de consumo. Assim, o incremento do consumo induz ao aumento da procura por bens, produtos e serviços que serão metabolizados nos processos de consumo, resultando em saídas de resíduos diversos. Os processos produtivos também geram externalidades negativas quando os impactos da produção não são adequadamente minimizados.

Sob estas circunstâncias, o modelo econômico linear apresenta algumas limitações, tais como: perdas econômicas através do desperdício; a exploração de determinados recursos naturais pode levar à volatilidade dos preços e da oferta em níveis mundiais e a degradação dos sistemas naturais, a qual leva ao esgotamento de reservas naturais (ELLEN MACARTHUR FOUNDATION, 2013b).

Observando a Figura 1, percebe-se que a Economia Linear leva à perda desnecessária de recursos: um volume significante de materiais e energia é perdido na fase de produção. A quantidade de

$\begin{array}{llllll}\text { Caminhos de Geografia } & \text { Uberlândia - MG } & \text { v. 21, n. 73 } & \text { Mar/2020 } & \text { p. 70-85 } & \text { Página } 71\end{array}$


materiais recuperados após o fim de sua vida útil é muito baixa, o que também leva a perda de materiais úteis no sistema. Nota-se que o capital natural também é reduzido quando os recursos naturais são utilizados de forma insustentável.

Figura 1 - Economia linear e as perdas de matéria e energia.

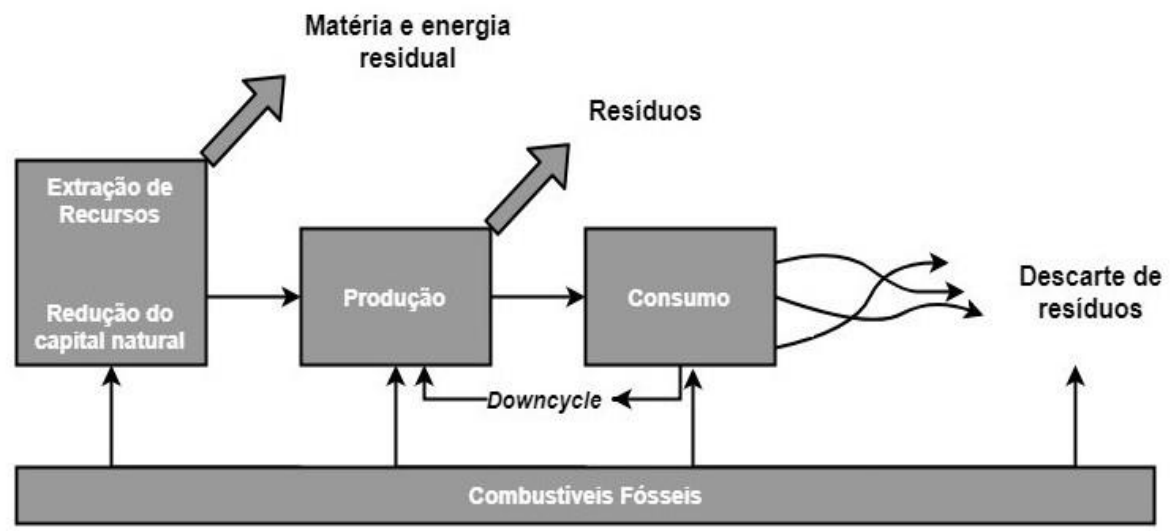

Fonte: Ellen MacArthur Foundation (2018) traduzido e adaptado pelos autores.

Em um sistema linear, o descarte de resíduos faz com que com toda a energia residual presente nos materiais seja perdida na forma de rejeitos depositados em aterros e lixões. Nota-se, que a maioria da perda de materiais ocorre nos primeiros estágios de extração e produção, ou seja, a fase do préconsumo. O mesmo ocorre com o uso da energia.

Diante de tais problemas, surge a necessidade de pensar em uma nova forma de criação de valor econômico. Neste contexto, nasce a Economia Circular. O conceito deste termo ainda vem sendo moldado, mas a ideia subjacente à Economia Circular já existia. Segundo Murray et al. (2015) os primeiros registros que faziam alusão à Economia Circular são do ano de 1848: Hofman, o primeiro presidente da Royal Society of Chemistry fez a seguinte declaração: "numa indústria química ideal, literalmente falando, não existe lixo, e sim apenas produtos. Quanto melhor uso a indústria faz de seu lixo, mais perto ela chega de seu ideal e maior será o lucro gerado". Posteriormente em 1966, o economista britânico Kenneth Boulding pontua em suas obras, que o homem deve achar o seu lugar num sistema ecológico cíclico, o qual seja capaz da reprodução contínua de materiais naturais. Em 1980, Stahel e Reday-Mulvey descreveram um sistema fechado de interações econômicas e ambientais, dando destaque à durabilidade de produtos. Em 1991, o cientista sueco Karl-Henrik Robèrt declarou que a maioria dos problemas ambientais são baseados no mesmo erro sistêmico: 0 sistema linear de produção.

O termo "Economia Circular" apresenta, portanto, uma variedade de significados desenvolvidos por diversos autores que convergem para uma única ideia: um sistema cíclico e fechado de produção. Além disso, a abordagem deste novo tema fez surgir as seguintes escolas de pensamento: a Economia de Performance (STAHEL, 2010); o Cradle to Cradle ou Berço ao Berço (BRAUNGART e MCDONOUGH, 2014); a Biomimética (BENYUS, 2003), o Capitalismo Natural (LOVINS, 2000), o Design Regenerativo (EMF, 2013a), a Ecologia Industrial (CLIFT e DRUCKMAN, 2016) e a Blue Economy por Gunter Pauli (EMF, 2013b). Estes autores descontroem a ideia de que apenas há desenvolvimento econômico quando se faz uso de recursos naturais finitos.

\section{Principais Referências}

Nos parágrafos seguintes discute-se os principais pontos apresentados pelos autores segundo as escolas de pensamento.

De acordo com EMF (2013a), a origem específica do termo Economia Circular não pode ser atribuída a apenas um autor, são escolas de pensamentos diferentes, que de alguma forma, têm um mesmo sentido. 
Um dos principais autores, que discorre sobre a Economia Circular é Walter Stahel, fundador do Product Life Institute, sendo um dos objetivos vender serviços ao invés de produtos. A economia de serviços é uma das principais escolas de pensamento da Economia Circular: o valor da utilização de serviços e produtos é a noção central de valor econômico. Segundo Stahel (2010) a propriedade dos produtos ou serviços oferecidos é de domínio do produtor, enquanto o usuário dos produtos e serviços pagam apenas o aluguel pelo uso dos mesmos. Uma ilustração desta escola de pensamento é a economia de serviços da Michelin, fabricante de pneus. Ao contrário do usual, a empresa não vende pneus novos a cada troca e sim, a quilometragem dos pneus. Assim, quando um pneu precisa ser trocado, na própria empresa é feito o reparo do pneu para que este esteja em condições de uso e o usuário paga a quilometragem que utilizar. Observa-se que essa estratégia irá diminuir a deposição de pneus velhos em ruas, lixões ou aterros.

Braungart e Mcdonough (2014), por meio de sua filosofia "Cradle to Cradle" (Berço ao Berço) defendem, que os materiais considerados obsoletos devem servir como fonte de material secundário para outras linhas de produção. São os fluxos de nutrientes biológicos e os nutrientes técnicos (Figura 2). Os materiais secundários sempre se encaixam em um destes fluxos, dessa forma, eles são reincorporados na cadeia de produção e o que seria rejeito, se transforma em recurso (waste equals food). Para que isso ocorra, no processo de criação do produto, todos os seus materiais e componentes são escolhidos de forma, que ao fim da vida útil dos mesmos, eles sejam utilizados como nutrientes nos fluxos biológicos e técnicos (design out waste).

Figura 2 - Ciclos biológicos e ciclos técnicos na Economia Circular.

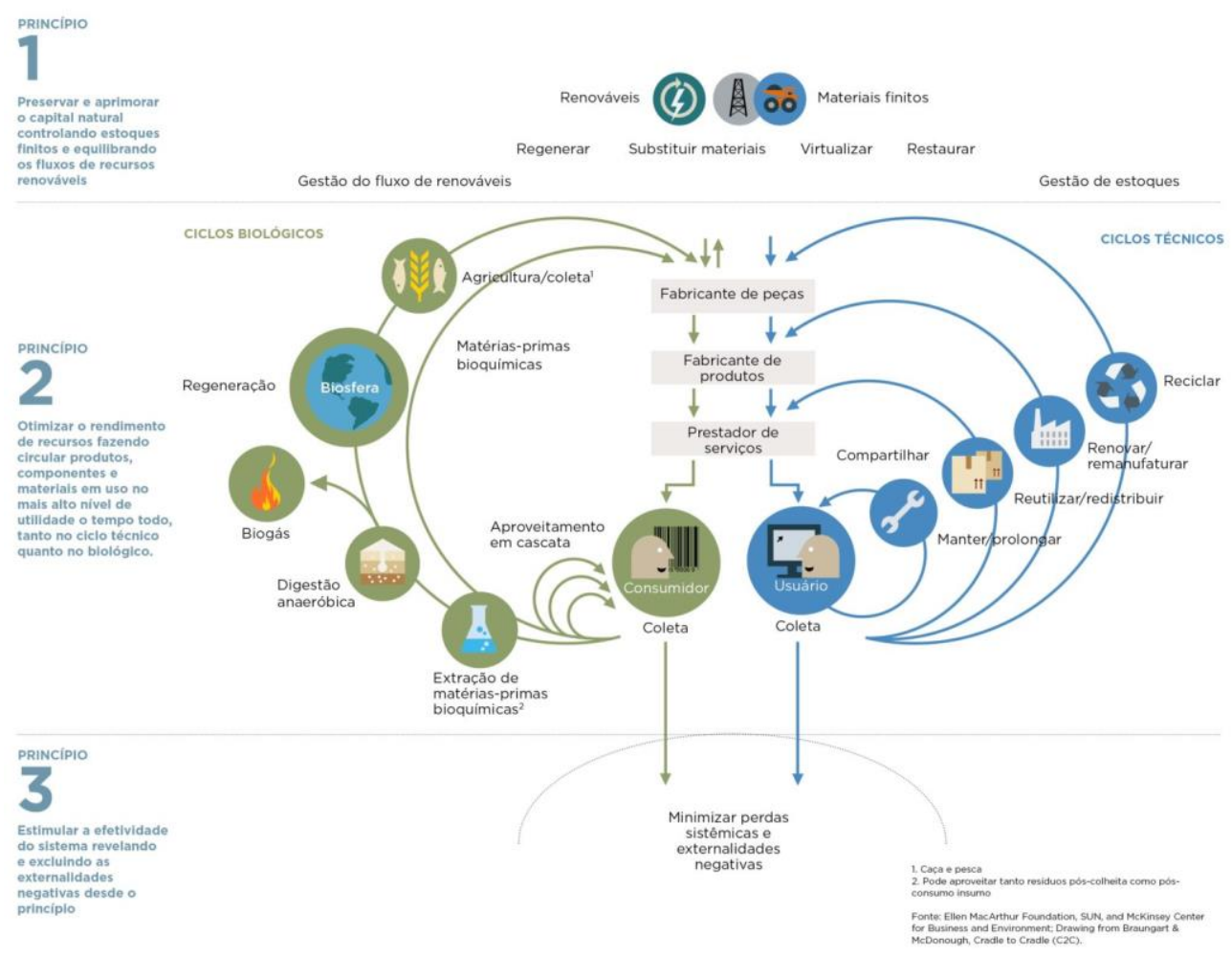

Fonte: Ellen MacArthur Foundation Brasil (EMF), (2019).

Benyus (2003) sugere que, os modelos, sistemas e elementos da natureza sejam imitados, para que os problemas humanos em relação à sustentabilidade sejam resolvidos. Para isso se dá a denominição de biomimética: "quanto maior for a semelhança entre o nosso mundo e o mundo natural, maior é a probabilidade de nele se sobreviver". A Biomimética, segundo Benyus (2003) baseia-se em três pilares:

a) a natureza é como um modelo - realiza-se estudos das formas, processos e sistemas da natureza, para que sejam emulados na vida humana, com o objetivo de resolver problemas;

b) a natureza é como um medidor - utiliza-se um padrão ecológico, para julgar o nível de sustentabilidade das inovações;

c) a natureza é como uma mentora - defende-se não basear o valor da natureza no que se pode extrair dela, mas sim do que se pode aprender a partir dela.

$\begin{array}{llllll}\text { Caminhos de Geografia } & \text { Uberlândia - MG } & \text { v. } 21, \text { n. } 73 & \text { Mar/2020 } & \text { p. } 70-85 & \text { Página } 73\end{array}$


Hawken, A. Lovins e H. Lovins (2000) disseminam o Capitalismo Natural: o investimento nos ecossistemas para o desenvolvimento econômico, estabelecendo que o desenvolvimento da economia só é possível quando existe a devida manutenção dos ecossistemas.

John T. Lyle discorre sobre o Design Regenerativo, conforme apresentado nos relatórios da EMF (2013a). De acordo com o autor, todos os sistemas podem ser gerenciados de forma regenerativa: os sistemas por si só poderiam gerar ou renovar as fontes de energia e materiais que eles consomem.

A Ecologia Industrial é a escola de pensamento de Clift e Druckman (2016). Esta teoria consiste no estudo dos fluxos de materiais e energia nos sistemas industriais. Os autores sugerem que, dentro dos sistemas industriais sejam criados ciclos fechados, para que as sobras dos processos produtivos sirvam de matéria para outro tipo de produção. Esse ciclo fechado interfere diretamente na cadeia de matérias primas naturais, influenciando assim, os aspectos ambientais e sociais do mundo.

Além da literatura formal, há um movimento denominado Blue Economy criado por Gunter Pauli, que se baseia em 21 princípios. O movimento defende a criação de soluções considerando as características ambientais, ecológicas e físicas de cada local. É dado ênfase no uso em cascata dos recursos disponíveis, empregando-se uma estratégia, na qual as sobras de um processo produtivo se transformam em recursos e energia para outro processo produtivo (ELLEN MACARTHUR FOUNDATION, 2013b).

Em meados de 2012, a EMF realizou um grande apanhado de tais escolas de pensamento, onde foram criados definições e princípios para a Economia Circular, tornando-se uma organização de grande relevância para o estudo e desenvolvimento do tema.

Desse modo, observa-se que os autores vinculados à temática da Economia Circular contribuem de formas diferentes para a inserção da circularidade na economia, seja pela reincorporação de matéria nos ciclos biológicos ou ciclos técnicos, seja pela observação do comportamento de ciclos da natureza, ou seja, pela necessidade de ordem econômica de reuso de materiais ou elementos em determinadas atividades.

\section{Princípios da Economia Circular}

Com a intenção de que, a Economia Circular não seja confundida apenas com um discurso teórico ou com uma prática facilmente maleável, a EMF (2013a) estabelece cinco princípios básicos, listados e explicados no Quadro 1.

Quadro 1 - Princípios básicos da Economia Circular.

\begin{tabular}{|c|c|}
\hline \multirow[b]{2}{*}{1} & CRIANDO RESILIÊNCIA ATRAVÉS DO ESTÍMULO À DIVERSIDADE \\
\hline & $\begin{array}{l}\text { Diante da velocidade em que se dá o consumo em dias atuais, quanto maior a modularidade, } \\
\text { versatilidade e adaptabilidade de um produto, maior será a sua vida útil, seja por meio de } \\
\text { reutilização, atualização, manutenção, etc. Dessa forma, evita-se a obsolescência programada. } \\
\text { Além disso, cria-se um sistema mais estável e resiliente à mudanças externas. }\end{array}$ \\
\hline \multirow[b]{2}{*}{2} & USO DE ENERGIA RENOVÁVEL \\
\hline & $\begin{array}{l}\text { A energia necessária em todos os grandes ou pequenos ciclos de produção de bens e serviços } \\
\text { deve ser, prioritariamente, energia renovável. }\end{array}$ \\
\hline & NÃO GERAÇÃO DE RESÍDUOS \\
\hline 3 & $\begin{array}{l}\text { É o repensar durante o processo de concepção de produtos com o intuito de que o } \\
\text { reaproveitamento de seus elementos e partes sejam viáveis no fim do seu ciclo de vida. Os } \\
\text { componentes biológicos e técnicos se encaixam nos ciclos biológicos e técnicos } \\
\text { respectivamente. No ciclo biológico, a matéria biodegradável retorna em forma de } \\
\text { compostagem ou digestão anaeróbia. Já no ciclo técnico, polímeros, ligas e outros materiais } \\
\text { sintéticos são produzidos de forma que possam ser usados novamente em outros ciclos de } \\
\text { produção. }\end{array}$ \\
\hline
\end{tabular}




\begin{tabular}{|l|l|}
\hline 4 & PENSAMENTO SISTÉMICO / USO EM CASCATA \\
\cline { 2 - 3 } & $\begin{array}{l}\text { Não se deve avaliar cada elemento separadamente, mas se deve avaliar a forma como os } \\
\text { fluxos de matéria e energia se relacionam entre si, e como essas relações se dão no meio } \\
\text { como um todo. Quando não for possível reduzir o consumo de recursos; reusar, reformar ou } \\
\text { promover o uso em cascata. O objetivo é fazer com que os recursos que façam parte de } \\
\text { produtos ou serviços fique o maior tempo possível nos processos de produção. }\end{array}$ \\
\hline \multirow{5}{5}{5} & $\begin{array}{l}\text { CONVERTER DESPERDÍCIO EM NUTRIENTES } \\
\text { (waste is food), é necessário estabelecer o que vai para os ciclos biológicos (compostagem, } \\
\text { por exemplo) e o que vai para os ciclos técnicos (reaproveitamento de peças de um automóvel, } \\
\text { por exemplo) }\end{array}$ \\
\hline
\end{tabular}

Fonte: Ellen MacArthur Foundation (EMF), (2013a) traduzido e adaptado pelos autores.

Também é de suma importância destacar as formas de geração de valor econômico, que se encontram apresentadas e comentadas no Quadro 2.

Quadro 2 - Formas de criação de valor em uma Economia Circular.

\begin{tabular}{|c|c|}
\hline \multirow[b]{2}{*}{1} & A importância dos ciclos internos \\
\hline & Quanto menor o ciclo percorrido por um material, maior é o ganho e o valor agregado. \\
\hline \multirow[b]{2}{*}{2} & A importância dos ciclos mais longos \\
\hline & $\begin{array}{l}\text { Deve-se evitar a dissipação dos materiais na economia. Quanto maior o tempo de circulação } \\
\text { de um material na economia, maior é a maximização de benefícios. }\end{array}$ \\
\hline \multirow[b]{2}{*}{3} & O uso em cascata ou substituição \\
\hline & $\begin{array}{l}\text { Para prolongar a presença dos recursos na economia, quando esgotadas as formas de reuso, } \\
\text { analisar as possibilidades de remanufatura e reciclagem material para que sejam } \\
\text { reincorporados em novos ciclos. }\end{array}$ \\
\hline \multirow[b]{2}{*}{4} & O uso de substâncias puras, não tóxicas e segregáveis \\
\hline & $\begin{array}{l}\text { Quando estas substâncias são utilizadas, a reincorporação em novos ciclos, a qualidade } \\
\text { adquirida e a possibilidade de reaproveitamento de partes se tornam mais viáveis. }\end{array}$ \\
\hline
\end{tabular}

Fonte: Ellen MacArthur Foundation (EMF), (2013a) traduzido e adaptado pelos autores.

\section{Benefícios da Economia Circular}

Baseando-se nos estudos sobre a aplicação da Economia Circular na Europa, contidos no relatório da EMF (2013a), percebe-se benefícios, que podem ser agrupados em três grandes grupos: os econômicos, os ambientais e os sociais. Não por acaso, são estes os três pilares que, interagindo de forma holística, constituem o conceito de sustentabilidade (SACHS, 1986; 2004). Discute-se nas subseções seguintes estes três grupos de benefícios apontados por EMF (2013a).

\section{Benefícios Econômicos}

Dentre os benefícios econômicos citados pela EMF (2013a) estão:

a) crescimento econômico - ocorreria o aumento do Produto Interno Bruto (PIB), em razão do surgimento de novas atividades relacionadas à Economia Circular e o menor gasto na

$\begin{array}{lllll}\text { Caminhos de Geografia } \quad \text { Uberlândia - MG } & \text { v. 21, n. } 73 \quad \text { Mar/2020 } & \text { p. 70-85 } & \text { Página } 75\end{array}$


produção, devido à utilização inteligente dos recursos disponíveis. Como consequência, haveria a redução de custo líquido na produção de bens com vida útil de média duração;

b) criação de empregos - surgiria em função da necessidade de mão de obra em vários setores, como a reciclagem e remanufatura, logística reversa e na área da economia baseada em serviços. A inovação e o empreededorismo, que a Economia Circular proporciona também criaria novos postos de emprego;

c) inovação - o contexto que a Economia Circular cria é um espaço amplo que possibilita a inovação. As consequências seriam: um aumento no nível de desenvolvimento tecnológico, quanto à produção de melhores materiais a serem usados de forma inteligente e eficiente de mão de obra, bem como o uso energético.

\section{Benefícios Ambientais}

Dentre os beneficios ambientais citados pela EMF (2013a) estão:

a) diminuição dos Gases de Efeito Estufa (GEE) e do dióxido de carbono $\left(\mathrm{CO}_{2}\right)$ - com mudanças feitas no sistema de mobilidade e de alimentação seria possível diminuir os níveis de produção de $\mathrm{CO}_{2}$. Além disso, a emissão de GEE também seria reduzida, caso os resíduos orgânicos não fossem destinados aos aterros sanitários;

b) diminuição do consumo de materiais primários - estes são, dentre outros, os recursos do solo, da água e do ar. No contexto da Economia Circular ocorreria a redução do uso de matérias-primas virgens.

c) aumento da produtividade e conservação do solo - utilizando-se de técnicas capazes de devolver os nutrientes num ciclo, como a digestão anaeróbia e a compostagem, haveria também, maior produtividade do solo e seu valor como ativo aumentaria. Além disso, a necessidade do uso de fertilizantes sintéticos diminuiria consideravelmente.

\section{Benefícios Sociais}

Dentre os beneficios sociais citados pela EMF (2013a) estão:

a) aumento da renda financeira - o contexto da Economia Circular permitiria o aumento da renda familiar devido à redução do custo para a produção de bens e serviços. Isso faz com que o preço de produtos e serviços caiam. Dessa forma, o consumo é estimulado;

b) maior utilidade de produtos e serviços - os modelos circulares de produção e consumo permitem que produtos e serviços sejam úteis o maior tempo possível. Isso graças ao estímulo à diversidade, à modularidade, à versatilidade e à adaptabilidade de produtos;

c) redução da obsolescência programada - produtos feitos para durar mais e que possuam condições de reparos mais acessíveis possibilitam a diminuição do custo total de propriedade do cliente sobre tal produto.

\section{A MOTIVAÇÃO DA TRANSIÇÃO DA ECONOMIA LINEAR PARA A CIRCULAR}

Como já citado anteriormente, o modelo econômico vigente é linear e apresenta uma grande taxa de desperdício, já que é baseado na extração, produção, consumo e descarte. Diante desse fato, a transição do modelo linear para o modelo circular é motivada por uma série de fatores, que seguem um raciocínio lógico: o crescimento demográfico e a urbanização crescentes levam à uma exploração desenfreada das reservas naturais com a finalidade de alimentar o sistema econômico vigente; por sua vez, a crescente exploração de reservas naturais faz com que ocorra a escassez de insumos de produção e a consequente redução da oferta de produtos no mercado, fazendo com que ocorra uma variação no preço dos bens de consumo. Consequentemente, haverá um déficit na produção de bens e serviços em escala global. Todos estes fatores somados atingem o tripé da sustentabilidade, provocando uma insatisfação social crescente, devido à qualidade de vida afetada negativamente. A degradação ambiental impossibilitará o desenvolvimento de inúmeras atividades e as perdas econômicas incutidas no desperdício do atual modelo econômico serão inúmeras. EMF (2013a) cita em seu relatório os principais fatores de mudanças:

a) perdas econômicas: a forma como se dá a produção e o consumo de bens e serviços apresenta um grande nível de desperdício, tanto material como econômico. A fim de ilustrar esse tópico, nota-se que na Europa um automóvel fica estacionado $92 \%$ do tempo; $31 \%$ dos 
alimentos são desperdiçados e, mesmo em horário de trabalho, os escritórios são ocupados só de $35 \%$ a $50 \%$ do tempo;

b) risco de preços: com o modelo econômico linear atual, a volatilidade dos preços é uma preocupação que vem junto com a escassez de oferta de recursos naturais. Isto faz com que o crescimento econômico seja inibido e que o investimento de empresas seja desestimulado;

c) risco de oferta: as reservas de recursos naturais quase sempre não estão espalhadas pelo globo de maneira homogênea. Com isso, vários países dependem de importação de vários recursos naturais. A partir do momento que a segurança dessa grande cadeia de importação é ameaçada, a produção de bens e serviços também fica à mercê do risco de oferta;

d) degradação de sistemas naturais: o modelo linear de produção leva a várias externalidades negativas relacionadas aos sistemas naturais, que direta ou indiretamente, afetam a produtividade econômica global. A perda de biodiversidade, a mudança climática global, a poluição dos oceanos e a perda de capital natural estão entre as principais formas de degradação ambiental em nível global;

e) tendências regulatórias: diante de inúmeras externalidades negativas, as tendências regulatórias se mostram cada vez mais firmes no sentido de precificar os prejuízos. Nesse contexto, o modelo econômico circular, somado ao uso de recursos finitos e a um sistema econômico resiliente, ganha cada vez mais destaque;

f) avanços tecnológicos: a tecnologia da informação e o avanço da Internet permitiram novos modelos de negócios que não eram possíveis anteriormente;

g) modelos de negócios alternativos: o acesso ao serviço, ao invés do produto, é cada vez mais comum. São modelos de negócios baseados em compartilhamento e que são possíveis graças às novas tecnologias;

h) urbanização: estima-se um aumento contínuo da população e, com isso, muitas atividades baseadas no compartilhamento de serviços, conforme citado acima, serão realizadas, o que contribuirá para a economia do local em questão.

Portanto, percebe-se que a transição da Economia Linear para a Economia Circular é motivada por vários aspectos econômicos e não puramente por aspectos ambientais, visando a criação de uma economia mais resiliente e segura, que responda sem grande impacto às externalidades negativas, incluindo as ambientais.

\section{A TRANSIÇÃO APOIADA NA LEGISLAÇÃO}

O termo Economia Circular deve ser entendido como um conceito amplo e composto por várias ações. Para que este conceito não seja um mero discurso teórico e seja colocado em prática, seja na esfera pública ou na esfera privada, o uso de instrumentos legais se faz necessário. Nota-se que ao longo do desenvolvimento da história da legislação ambiental, o incentivo a ações, que remetam ao uso sustentável de recursos naturais, quase sempre, são motivadas por razões econômicas e não motivadas apenas por uma responsabilidade socioambiental.

Para Sanchez (2008), a origem e a difusão dos aspectos ambientais na legislação se deram ao fato da criação da National Environmental Policy Act (NEPA) e do Council on Environmental Quality (CEQ) na década de 70 nos Estados Unidos. O conselho de meio ambiente tinha o status equivalente ao conselho financeiro. Ou seja, as considerações ambientais e financeiras possuíam o mesmo status. Perceberam que para se criar uma política eficaz, seriam necessários dois enfoques: o enfoque teórico e o enfoque prático. Para isso criaram-se declarações, resoluções, leis ou diretrizes e o Environmetal Impact Statement (EIS) como um instrumento que serviria como meio para as ações ambientais se materializarem. Dessa forma, empresários e burocratas públicos necessitavam seguir as recomendações da NEPA e cumprir os requisitos estabelecidos no EIS para seguir adiante com seus projetos.

No Brasil, a difusão dos aspectos ambientais na legislação foi um reflexo do que já acontecia em países desenvolvidos: diante do significativo crescimento das atividades econômicas, surgia a necessidade de instruções formais sobre como ocorreria a implantação de projetos em determinadas áreas ambientais através dos Estudos Ambientais (EA). Com a criação dos $E A$, aqueles que possuíam projetos em áreas ambientais deveriam seguir o protocolo estabelecido, sendo passível de indenização a danos causados ao meio ambiente (SANCHEZ, 2008). Condições estas, que foram estabelecidas em 1981, com a criação na Política Nacional do Meio Ambiente (PNMA) (BRASIL, 1981). Assim, se dá tal relação, a qual baseia-se no interesse econômico e é moldada pela legislação ambiental.

$\begin{array}{llllll}\text { Caminhos de Geografia } & \text { Uberlândia - MG } & \text { v. 21, n. } 73 & \text { Mar/2020 } & \text { p. } 70-85 & \text { Página } 77\end{array}$


Pensando nesse sentido, a EMF apresentou uma metodologia para formuladores de políticas públicas, para que a transição apoiada na legislação possa ser mais rápida. Entre as ações apresentadas, citam-se: identificar as oportunidades em relação à Economia Circular; quantificar seus impactos; identificar as barreiras que prejudicam as oportunidades; mapear e priorizar intervenções políticas para ultrapassar tais barreiras e engajar as principais partes interessadas, também reconhecidos como stakeholders (Figura 3) (ELLEN MACARTHUR FOUNDATION, 2015).

Além da metodologia mencionada acima, recentemente no Reino Unido, foi criada a norma BS 8001 (BRITISH STANDARDS INSTITUTION, 2017). A primeira norma criada com o intuito de guiar e apresentar recomendações para aqueles que desejam adotar abordagens circulares em sua realidade. Sendo assim, as políticas públicas e os instrumentos legais têm um papel fundamental para que os princípios da Economia Circular sejam colocados em prática.

Figura 3 - Metodologia para acelerar a transição apoiada nas políticas públicas.

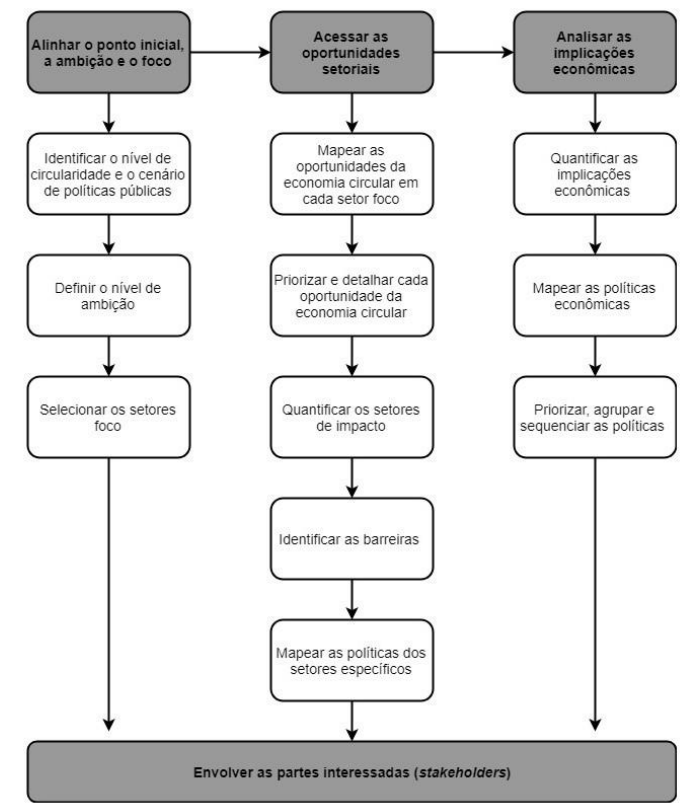

Fonte: Ellen MacArthur Foundation (EMF), (2015) traduzido e adaptado pelos autores.

\section{METODOLOGIA}

Baseando-se em Marconi e Lakatos (2003) a pesquisa foi realizada através das seguintes fases: escolha de um tema relevante e emergente para o meio acadêmico e para os formuladores de políticas públicas; levantamento de dados e informações através da pesquisa documental e bibliográfica; formulação do problema de pesquisa e a delimitação da pesquisa. Dentre as etapas elencadas, destaca-se a pesquisa bibliográfica, uma vez que a realização deste trabalho envolveu duas investigações distintas: (I) verificação dos intrumentos legais de gestão ambiental pública brasileira; (II) formação de um referencial teórico sobre o tema Economia Circular.

Ainda, baseando-se em Marconi e Lakatos (2003) a técnica empregada para a execução da pesquisa foi a coleta documental indireta em fontes primárias e secundárias, destacando-se os documentos oficiais e os arquivos particulares de instituições públicas e privadas.

Encerrada a coleta documental de dados e informações, realizou-se a análise do conteúdo reunido. Foi usada a técnica da seleção minuciosa dos dados e informações pertinentes na delimitação do tema da pesquisa. Posteriormente, foi realizada a análise e interpretação do material selecionado, objetivando estabelecer uma relação entre as informações obtidas e a hipótese da pesquisa.

Com base na literatura produzida pela EMF, a descrição dos princípios da Economia Circular foi confrontada com as políticas públicas ambientais e, particularmente, de resíduos sólidos, buscando uma correspondência de conteúdo. Os resultados foram apresentados em forma de matriz, relatando os pontos análogos entre os dois objetos de estudo. 


\section{RESULTADOS E DISCUSSÕES}

Apresenta-se nesta seção, a comparação dos instrumentos legais que regulamentam a gestão ambiental brasileira e do Estado de Goiás com os princípios da Economia Circular em forma de tópicos.

\section{Política Nacional De Meio Ambiente (PNMA)}

A PNMA foi instituída pela Lei 6938 , de 31 de agosto de 1981. Em seu Artigo 2ํㅡ, foi estabelecido que a PNMA tem por objetivo a preservação, melhoria e recuperação da qualidade ambiental propícia à vida, visando assegurar condições ao desenvolvimento socioeconômico, aos interesses da segurança nacional e à proteção da dignidade da vida humana, atendidos, dentre outros, os seguintes princípios:

II - racionalização do uso do solo, do subsolo, da água e do ar; [...]

$\mathrm{VI}$ - incentivos ao estudo e à pesquisa de tecnologias orientadas para o uso racional e a proteção dos recursos ambientais.

A confrontação do texto legal com a descrição dos princípios da Economia Circular resultou na identificação de uma relação, apontada no Quadro 3.

Quadro 3 - Matriz da PNMA x Princípios da Economia Circular

\begin{tabular}{|c|c|c|c|c|c|}
\hline \multirow{2}{*}{$\begin{array}{c}\text { Instrumento } \\
\text { legal } \\
\text { PNMA }\end{array}$} & \begin{tabular}{c}
\multicolumn{5}{|c|}{ Princípios da Economia Circular } \\
1) Resiliência \\
através da \\
diversidade
\end{tabular} & $\begin{array}{c}\text { 2) Energia } \\
\text { renovável }\end{array}$ & $\begin{array}{c}\text { 3) Não } \\
\text { geração de } \\
\text { resíduos }\end{array}$ & $\begin{array}{c}\text { 4)Pensamento } \\
\text { sistêmico }\end{array}$ & $\begin{array}{c}\text { 5) Desperdício } \\
\text { em nutriente }\end{array}$ \\
\hline Artigo 20 & - & - & - & Inciso II & - \\
\hline Artigo 20 & - & Inciso VI & - & Inciso VI & - \\
\hline
\end{tabular}

Fonte: elaborado pelos autores.

Nota-se que os incisos II e VI que estabelecem a racionalização no uso dos recursos ambientais, assim como o seu incentivo através de estudos e o uso da tecnologia demonstram a existência de um pensamento sistêmico (princípio 1), assim como na Economia Circular (Quadro 1), ou seja, a forma como a disponibilidade destes recursos influencia na qualidade ambiental propícia a vida e no desenvolvimento socioeconômico. Levando em consideração que os recursos naturais apresentam estoques finitos, é necessário haver uma redução no consumo de tais recursos no processo de produção de bens e serviços; quando tal ação não for possível, o uso em cascata de recursos se faz necessário, fazendo com que tal redução seja colocada em prática.

Além disso, o inciso VI pode ser relacionado ao princípio da energia renovável (princípio 2) da Economia Circular (Quadro 1), que diz respeito ao uso de energia renovável. O incentivo, a criação e a utilização de tecnologias voltadas para a racionalização do uso de recursos naturais impulsona a mudança da matriz energética atual, no sentido de incluir as fontes de energia renováveis.

Portanto, apesar da grande abrangência da PNMA em relação a vários tipos de atividades ambientais, os pontos em que a Economia Circular e o referido instrumento legal encontram-se são limitados e superficiais, necessitando assim, de um maior amadurecimento, no sentindo de incluir os princípios da Economia Circular na PNMA. Dessa forma, os pressupostos colocados pela Economia Circular se tornariam possíveis dentro da realidade da gestão ambiental pública brasileira.

\section{Política Nacional De Resíduos Sólidos (PNRS)}

A PNRS foi instituída pela Lei 12.305, de 2 de agosto de 2010. Vários artigos e incisos presentes na PNRS podem ser relacionados com os cinco princípios da Economia Circular, dentre eles, os artigos 6ㅇ ao 9o e alguns de seus incisos. No Artigo 6으, referem-se aos princípios da PNRS os incisos seguintes: 
III - a visão sistêmica, na gestão dos resíduos sólidos, que considere as variáveis ambiental, social, cultural, econômica, tecnológica e de saúde pública; [...]

V - a ecoeficiência, mediante a compatibilização entre o fornecimento, a preços competitivos, de bens e serviços qualificados que satisfaçam as necessidades humanas e tragam qualidade de vida e a redução do impacto ambiental e do consumo de recursos naturais a um nível, no mínimo, equivalente à capacidade de sustentação estimada do planeta; [...]

VII - a responsabilidade compartilhada pelo ciclo de vida dos produtos;

VIII - o reconhecimento do resíduo sólido reutilizável e reciclável como um bem econômico e de valor social, gerador de trabalho e renda e promotor de cidadania.

No Artigo $7^{\circ}$, os incisos abrangem os objetivos da PNRS e destacam-se os seguintes:

II - não geração, redução, reutilização, reciclagem e tratamento dos resíduos sólidos, bem como disposição final ambientalmente adequada dos rejeitos; [...]

IV - adoção, desenvolvimento e aprimoramento de tecnologias limpas como forma de minimizar impactos ambientais; [...]

$\mathrm{VI}$ - incentivo à indústria da reciclagem, tendo em vista fomentar o uso de matérias-primas e insumos derivados de materiais recicláveis e reciclados;

VII - gestão integrada de resíduos sólidos;

VIII - articulação entre as diferentes esferas do poder público, e destas com o setor empresarial, com vistas à cooperação técnica e financeira para a gestão integrada de resíduos sólidos; [...]

XI - prioridade, nas aquisições e contratações governamentais, para: a) produtos reciclados e recicláveis; b) bens, serviços e obras que considerem critérios compatíveis com padrões de consumo social e ambientalmente sustentáveis;

XII - integração dos catadores de materiais reutilizáveis e recicláveis nas ações que envolvam a responsabilidade compartilhada pelo ciclo de vida dos produtos;

XIII - estímulo à implementação da avaliação do ciclo de vida do produto;

XIV - incentivo ao desenvolvimento de sistemas de gestão ambiental e empresarial voltados para a melhoria dos processos produtivos e ao reaproveitamento dos resíduos sólidos, incluídos a recuperação e o aproveitamento energético.

Previsto no Artigo 8ํㅜㄹ que estabelece os instrumentos da PNRS estão:

III - a coleta seletiva, os sistemas de logística reversa e outras ferramentas relacionadas à implementação da responsabilidade compartilhada pelo ciclo de vida dos produtos;

IV - o incentivo à criação e ao desenvolvimento de cooperativas ou de outras formas de associação de catadores de materiais reutilizáveis e recicláveis; [...]

$\mathrm{VI}$ - a cooperação técnica e financeira entre os setores público e privado para o desenvolvimento de pesquisas de novos produtos, métodos, processos e tecnologias de gestão, reciclagem, reutilização, tratamento de resíduos e disposição final ambientalmente adequada de rejeitos.

E por fim, o Artigo 9ำ que aborda as diretrizes aplícaveis aos resíduos sólidos:

Art. 9ำ $\mathrm{Na}$ gestão e gerenciamento de resíduos sólidos, deve ser observada a seguinte ordem de prioridade: não geração, redução, reutilização, reciclagem, tratamento dos resíduos sólidos e disposição final ambientalmente adequada dos rejeitos.

O Quadro 4 apresenta a relação observada entre os artigos e seus respectivos incisos presentes na PNRS e os princípios estabelecidos pela Economia Circular. 
Quadro 4 - Matriz da PNRS x Princípios da Economia Circular.

\begin{tabular}{|c|c|c|c|c|c|}
\hline \multirow[b]{2}{*}{$\begin{array}{c}\text { Instrumento legal } \\
\text { PNRS }\end{array}$} & \multicolumn{5}{|c|}{ Princípios da Economia Circular } \\
\hline & $\begin{array}{l}\text { 1) Resiliência } \\
\text { através da } \\
\text { diversidade }\end{array}$ & $\begin{array}{l}\text { 2) Energia } \\
\text { renovável }\end{array}$ & $\begin{array}{l}\text { 3) Não } \\
\text { geração de } \\
\text { resíduos }\end{array}$ & $\begin{array}{l}\text { 4)Pensamento } \\
\text { sistêmico }\end{array}$ & $\begin{array}{c}5) \\
\text { Desperdício } \\
\text { em } \\
\text { nutriente }\end{array}$ \\
\hline Artigo $6^{\circ}$ e $7^{\circ}$ & $\begin{array}{l}\text { Artigo } 6^{\circ} \\
\text { Inciso V }\end{array}$ & $\begin{array}{l}\text { Artigo } 7^{\circ} \\
\text { Inciso IV }\end{array}$ & $\begin{array}{l}\text { Artigo } 7^{\circ} \\
\text { Inciso II } \\
\text { Inciso VI }\end{array}$ & $\begin{array}{l}\text { Artigo 60 } \\
\text { Inciso III } \\
\text { Inciso V } \\
\text { Inciso VII } \\
\text { Inciso VIII }\end{array}$ & $\begin{array}{l}\text { Artigo 6을 } \\
\text { Inciso VIII }\end{array}$ \\
\hline Artigo $7^{\circ}$ e $9^{\circ}$ & - & - & Artigo $9^{\circ}$ & $\begin{array}{l}\text { Artigo 70 } \\
\text { Inciso II } \\
\text { Inciso IV } \\
\text { Inciso VI } \\
\text { Inciso VII } \\
\text { Inciso VIII } \\
\text { Inciso XI } \\
\text { Inciso XII } \\
\text { Inciso XIII } \\
\text { Inciso XIV }\end{array}$ & $\begin{array}{l}\text { Artigo } 7^{\circ} \\
\text { Inciso VI } \\
\text { Inciso XIV }\end{array}$ \\
\hline Artigo $8^{\circ}$ & - & - & - & $\begin{array}{l}\text { Artigo } 8^{\circ} \\
\text { Inciso III } \\
\text { Inciso IV } \\
\text { Inciso VI }\end{array}$ & - \\
\hline Artigo 9응 & - & - & - & Artigo $9^{\circ}$ & - \\
\hline
\end{tabular}

Fonte: elaborado pelos autores.

Constata-se então, que o Artigo $6^{\circ}$ em seu inciso $V$ define a ecoeficência como um princípio da PNRS. Relaciona-se este inciso com o princípio da resiliência através do estímulo a diversidade (princípio 1) da Economia Circular (Quadro 1). O incentivo à ecoeficiência através da compatibilização entre fornecimento; preços competitivos; qualidade dos bens e serviços; impacto ambiental mínimo e consumo consciente de recursos naturais são ações que estimulam a diversificação de bens e serviços. Cria-se dessa forma, um sistema mais estável e menos vulnerável frente às mudanças externas.

O Artigo $7^{0}$ e seu inciso IV, definido pela "adoção, desenvolvimento e aprimoramento de tecnologias limpas como forma de minimizar impactos ambientais", pode ser relacionado ao princípio do uso de energia renovável (princípio 2) da Economia Circular (Quadro 1). Essa relação determina a necessidade de adoção de novas práticas, no que diz respeito ao uso de matérias primas finitas para a produção de energia necessária em um processo produtivo. Isso incentiva mudanças no uso da energia convencional para a energia renovável.

Analisando o Artigo $7^{\circ}$ e seus incisos II e VI e o Artigo 9ำ, percebe-se que todos eles têm um ponto em comum: estabelecem a não geração de resíduos sólidos como prioridade e, posteriormente, as práticas de redução, reutilização, reciclagem e o tratamento ambientalmente adequado dos resíduos sólidos. Esse é um processo que pode ser relacionado ao princípio da não geração de resíduos (princípio 3) da Economia Circular (Quadro 1). Tal princípio estabelece, que os produtos devem ser pensados desde a sua concepção, criando-os de forma que, ao fim de sua vida útil, eles possam ser reincorporados novamente no processo produtivo.

O Artigo 6ํㅡ e seu inciso VIII, juntamente com o Artigo $7^{\circ}$ e seus incisos VI e XIV relacionam-se com o princípio de converter desperdício em nutrientes (princípio 5) da Economia Circular (Quadro 1). 
Reconhecer o resíduo sólido como um bem econômico e de transformação social; incentivar o uso de resíduos sólidos recicláveis e reutilizáveis e estimular o desenvolvimento de processos produtivos que recuperem os resíduos reutilizáveis, assim como o seu aproveitaento energético, são ações que remetem e incentivam a criação de ciclos técnicos no processo de produção de bens e serviços.

Um maior número de artigos e incisos da PNRS podem ser relacionados ao princípio do pensamento sistêmico (princípio 4) da Economia Circular (Quadro 1). Isso, porque todos estes incisos levam em consideração a interação das partes da gestão integrada dos resíduos sólidos com todo o cenário e suas conexões. Nota-se que todos os incisos citados buscam, de diferentes formas, reforçar a prática da gestão integrada dos resíduos sólidos em âmbito nacional.

Assim sendo, constata-se que outros pontos análogos entre a PNRS e a Economia Circular são identificados, porém, eles são muito repetitivos, superficiais e não abrangem por completo os princípios da Economia Circular. Por exemplo, a logística reversa é o instrumento mais citado e que se relaciona diretamente à Economia Circular e à alimentação de ciclos técnicos e biológicos.

\section{Política Estadual de Resíduos Sólidos}

A Política de Resíduos Sólidos do Estado de Goiás foi instituída pela Lei 14.248 de 29 de julho de 2002. Ela apresenta em alguns de seus artigos e incisos, princípios e objetivos que são análogos aos princípios da Economia Circular. Sendo assim, destaca-se os Artigos $2^{\circ}$ e $3^{\circ}$ e alguns de seus incisos.

Está previsto no Artigo $2^{\circ}$ e em alguns incisos que abordam os princípios da política:

II - o gerenciamento integrado através da articulação entre o Poder Público, os produtores e demais segmentos da sociedade civil; [...]

VIII - a prevenção da poluição, mediante práticas que promovam a redução ou eliminação de resíduos na fonte geradora;

IX - a minimização dos resíduos, por meio do incentivo às práticas ambientalmente adequadas de reutilização, reciclagem e recuperação, e que busquem evitar sua geração.

Está previsto no Artigo 3o e seus incisos que abrangem os objetivos da política:

I - articular, potencializar e efetivar ações de prevenção da poluição para a eliminação ou, pelo menos, a redução da geração de redução da geração de resíduos sólidos na fonte; [...]

III - promover ações de reutilização, reciclagem, recuperação, coleta, transporte, tratamento e disposição final dos resíduos e assegurar uma utilização adequada e racional dos recursos naturais para a presente e as futuras gerações;

$\mathrm{V}$ - promover ações direcionadas à criação de mercados locais e regionais para os materiais recicláveis e reciclados; [...]

VII - fomentar o consumo, pelos organismos e agentes públicos, de produtos originados total ou parcialmente com material reciclado e de produtos em cujo ciclo de vida os resíduos sejam eliminados ou, pelo menos reduzidos.

O quadro 5 ilustra o encontro dos pontos análogos da política com os princípios da Economia Circular: 
Quadro 5 - Matriz da Política Estadual de Resíduos Sólidos x Princípios da Economia Circular.

\begin{tabular}{|c|c|c|c|c|c|}
\hline \multirow[b]{2}{*}{$\begin{array}{c}\text { Instrumento legal } \\
\text { PERS }\end{array}$} & \multicolumn{5}{|c|}{ Princípios da Economia Circular } \\
\hline & $\begin{array}{l}\text { 1) Resiliência } \\
\text { através da } \\
\text { diversidade }\end{array}$ & $\begin{array}{l}\text { 2) Energia } \\
\text { renovável }\end{array}$ & $\begin{array}{l}\text { 3) Não } \\
\text { geração de } \\
\text { resíduos }\end{array}$ & $\begin{array}{l}\text { 4)Pensamento } \\
\text { sistêmico }\end{array}$ & $\begin{array}{c}\text { 5) } \\
\text { Desperdício } \\
\text { em nutriente }\end{array}$ \\
\hline Artigo $2^{\circ}$ & - & - & Inciso VIII & $\begin{array}{l}\text { Inciso II } \\
\text { Inciso VIII } \\
\text { Inciso IX }\end{array}$ & - \\
\hline Artigo 3ำ & - & - & $\begin{array}{l}\text { Inciso I } \\
\text { Inciso VII }\end{array}$ & $\begin{array}{l}\text { Inciso I } \\
\text { Inciso III } \\
\text { Inciso V } \\
\text { Inciso VII }\end{array}$ & Inciso VII \\
\hline
\end{tabular}

Fonte: elaborado pelos autores.

O princípio da não geração de resíduos (princípio 3) da Economia Circular (Quadro 1), relaciona-se ao Artigo $2^{\circ}$, inciso VIII e o Artigo $3^{\circ}$, incisos I e VII. Esta relação é estabelecida pela enfatização das práticas da não geração de resíduos sólidos no berço dos produtos, ou seja, é incentivado o pensamento da não geração desde a sua concepção, criando-os de forma com que todas as suas partes possam ser reincorporadas nos ciclos biológicos ou técnicos.

O artigo $2^{\circ}$ e seus incisos II e IX, e o Artigo $3^{\circ}$ e seus incisos III, V e VII relacionam-se ao princípio do pensamento sistêmico (princípio 4) da Economia Circular (Quadro 1). Estes incisos levam em consideração a gestão integrada dos resíduos sólidos; ações que enfatizam a sua não geração e ao uso de produtos e materiais recicláveis, fomentando assim, o mercado de recicláveis. Gestão integrada esta, que será promovida através de parcerias entre agentes públicos e privados para que a qualidade socioambiental seja mantida ou até mesmo melhorada. Ou seja, são ações que parecem ser isoladas, mas que em conjunto dão impulso para que as práticas da economia circular sejam viáveis.

Além disso, o Artigo $3^{\circ}$ e seu inciso VII também se relaciona ao princípio da conversão do desperdício em nutrientes (princípio 5) da Economia Circular (Quadro 1). Isto, porque fomentar o consumo de produtos parcialmente ou totalmente feitos de material reciclável e de produtos cujo os resíduos são diminuídos ou eliminados durante seu ciclo de vida, são ações que alimentam o movimento dos ciclos biológicos e ciclos técnicos.

Portanto, apesar de extensa, a Política Estadual de Resíduos Sólidos apresenta apenas dois Artigos que podem ser relacionados à três princípios da Economia Circular, se mostrando imatura no que se refere à existência das práticas da à Economia Circular na gestão ambiental à nível estadual.

\section{CONSIDERAÇÕES FINAIS}

Embasada em escolas de pensamento já consolidadas há tempos, a Economia Circular mostra-se um tema abrangente e emergente, que vem sendo estudado e aplicado principalmente na União Europeia. É um novo paradigma que apresenta vantagens econômicas, ambientais e sociais, ou seja, é o que mais se aproxima do conceito de Desenvolvimento Sustentável.

Adentrando no contexto brasileiro, percebe-se que a ampliação da legislação ambiental teve início na década de 80, principalmente através da criação da PNMA. Entretanto, nota-se que ao longo dos anos não houve a sua atualização para acompanhar as mudanças na sociedade e na economia como um todo. A criação da PNRS em 2010, ou seja, 30 anos depois da PNMA, ilustra o vácuo de tempo existente entre 0 instrumento legal norteador da gestão ambiental pública brasileira e aquele que define diretrizes para a componente resíduos sólidos do saneamento básico.

$\mathrm{Na}$ tentativa de encontrar pontos análogos entre os princípios da Economia Circular e os instrumentos legais de gestão ambiental pública brasileira, constatou-se que estes são poucos ou quase inexistentes. Apesar disso, a PNMA e a PNRS apresentam diretrizes para o planejamento e para a gestão ambiental, tanto pública como privada, que têm a capacidade de incorporar os princípios da 
Economia Circular. Estes últimos, se incorporados à legislação ambiental brasileira, possibilitariam o alcance de benefícios econômicos, ambientais e sociais.

Caso não ocorra a atualização dos instrumentos legais brasileiros e estaduais relativos à gestão ambiental pública, naquilo que se refere ao paradigma emergente da Economia Circular, um novo vácuo de tempo está se formando.

Para que as práticas da Economia Circular se consolidem no Brasil, é necessário o aprimoramento dos instrumentos legais de gestão ambiental pública. É preciso identificar e alterar neles, pontos que dificultam as ações voltadas à Economia Circular.

\section{REFERÊNCIAS}

BENYUS, J. Biomimética. 1. ed. São Paulo: Cultrix, 2003.

BRASIL. Lei n. 12.305 de 2 de agosto de 2010. Institui a Política Nacional de Resíduos Sólidos; altera a Lei no 9.605, de 12 de fevereiro de 1998; e dá outras providências. Diário Oficial da União, Poder Executvo, Brasília, DF, 03 ago. 2010. Seção 1, p. 3. Disponível em: <http://www.planalto.gov.br/ccivil_03/_Ato2007-2010/2010/Lei/L12305.htm>. Acesso em: 17 abr. 2018

BRASIL. Lei n. 6.938 de 31 de agosto de 1981. Dispõe sobre a Polítca Nacional do Meio Ambiente, seus fins e mecanismos de formulação e aplicação, e dá outras providências. Diário Oficial da União, Poder Executivo, Brasília, DF, 02 set. 1981. Seção 1, p. 16509. Disponível em: <http://www.planalto.gov.br/ccivil_03/LEIS/L6938.htm>. Acesso em: 17 abr. 2018

BRAUNGART, M.; MCDONOUGH, W. Cradle to Cradle: Criar e Reciclar llimitadamente. 1. ed. São Paulo: Gustavo Gili Brasil, 2014.

BRITISH STANDARDS INSTITUTION. BS 8001. Framework for implementing the principles of the circular economy in organizations. Guide. 2017.

CLIFT, R.; DRUCKMAN, A. Taking Stock of Industrial Ecology. 1. ed. Guildford: Springer open, 2016. https://doi.org/10.1007/978-3-319-20571-7

ELLEN MACARTHUR FOUNDATION BRASIL. Economia Circular. Diagrama sistêmico. Disponível em: <https://www.ellenmacarthurfoundation.org/pt/economia-circular-1/diagrama-sistemico>. Acesso em: 01 set. 2019.

ELLEN MACARTHUR FOUNDATION. Delivering the Circular Economy: a toolkit for policymakers. Cowes: Founding Partners of the Ellen MacArthur Foundation, v. 1, 2015. Disponível em: $<$ https://www.ellenmacarthurfoundation.org/assets/downloads/publications/EllenMacArthurFoundation PolicymakerToolkit.pdf>. Acesso em: 01 set. 2019.

ELLEN MACARTHUR FOUNDATION. Towards the Circular Economy: economic and business rationale for an accelerated transition. Cowes: Founding Partners of the Ellen MacArthur Foundation, v. 1 2013a. Disponível em: $<$ https://www.ellenmacarthurfoundation.org/assets/downloads/publications/Ellen-MacArthur-

Foundation-Towards-the-Circular-Economy-vol.1.pdf>. Acesso em: 01 set. 2019.

ELLEN MACARTHUR FOUNDATION. Towards the Circular Economy: opportunities for the consumer goods sector. Cowes: Founding Partners of the Ellen MacArthur Foundation, v. 2, 2013b. Disponível em: <https://www.ellenmacarthurfoundation.org/publications/towards-the-circular-economyvol-2-opportunities-for-the-consumer-goods-sector>. Acesso em: 01 set. 2019

GOIÁS (Estado). Lei n. 14.248 de 29 de julho de 2002. Dispõe sobre a Política Estadual de Resíduos Sólidos e dá outras providências. Disponível em:<http://www.gabinetecivil.goias.gov.br/leis_ordinarias/2002/lei_14248.htm>. Acesso em: 17 abr. 2018.

HAWKEN, P.; LOVINS, A.; LOVINS, H. Capitalismo Natural: criando a próxima revolução industrial. 1. ed. São Paulo: Cultrix, 2000.

INSTITUTO BRASILEIRO DE GEOGRAFIA E ESTATÍSTICA. Ministério do Planejamento, Orçamento e gestão. Pesquisa Nacional De Saneamento Básico 2008. Rio de Janeiro, 2010. 219 p.

MARCONI, M. de A.; LAKATOS, E. M. Fundamentos de Metodologia Científica. 5. ed. São Paulo: Atlas, 2003. 
MONTEIRO, J.H.P. Manual de Gerenciamento Integrado de Resíduos Sólidos. Rio de Janeiro: IBAM, 2001, $200 \mathrm{p}$.

MURRAY, A.; SKENE, K.; HAYNES, K. The Circular Economy: An Interdisciplinary Exploration of the Concept and Application in a Global Context. Journal of Business Ethics, Dordrecht, v. 140, n. 3, p.369-380, 22 maio 2015. Springer Nature. http://dx.doi.org/10.1007/s10551-015-2693-2. Disponível em:<https://link.springer.com/article/10.1007/s10551-015-2693-2>. Acesso em: 25 jan. 2018. https://doi.org/10.1007/s10551-015-2693-2

SACHS, I. Ecodesenvolvimento: crescer sem destruir. São Paulo: Vértice, 1986.

SACHS, I. Experiências internacionais de um cientista inquieto - Entrevista com Ignacy Sachs. Estudos Avançados, v. 18, 52. ed. São Paulo: 2004. Disponível em: <http://www.scielo.br/scielo.php?script=sci_arttext\&pid=S0103-40142004000300023 >. Acesso em: 12 set. 2019. https://doi.org/10.1590/S0103-40142004000300023

SANCHEZ, L. H. Avaliação de Impacto Ambiental: conceitos e métodos. 1 ed. São Paulo: Oficina de Textos, 2008.

STAHEL, W. R. The Performance Economy. 2 ed. Great Britain: Palgrave Macmillan. 2010. https://doi.org/10.1057/9780230288843

VILHENA, A. Lixo municipal: manual de gerenciamento integrado. 4. ed. São Paulo: CEMPRE, 2018. 316p.

Recebido em: 07/03/2019

Aceito para publicação em: 30/08/2019 